\title{
Joint enterprise and the role of the intermediator
}

Challenges managing groupware in global virtual teams

Bjørn, Pernille; Simonsen, Jesper

Published in:

DEXA 2005, Sixteenth International Workshop on Database and Expert Systems Applications

DOI:

10.1109/DEXA.2005.123

Publication date:

2005

Document Version

Publisher's PDF, also known as Version of record

Citation for published version (APA):

Bjørn, P., \& Simonsen, J. (2005). Joint enterprise and the role of the intermediator: Challenges managing groupware in global virtual teams. In W. Wieczerzycki (Ed.), DEXA 2005, Sixteenth International Workshop on Database and Expert Systems Applications: 5th International Workshop on Web Based collaboration W10, WBC'05 (pp. 609-615). IEEE Computer Society Press. https://doi.org/10.1109/DEXA.2005.123

\section{General rights}

Copyright and moral rights for the publications made accessible in the public portal are retained by the authors and/or other copyright owners and it is a condition of accessing publications that users recognise and abide by the legal requirements associated with these rights.

- Users may download and print one copy of any publication from the public portal for the purpose of private study or research.

- You may not further distribute the material or use it for any profit-making activity or commercial gain.

- You may freely distribute the URL identifying the publication in the public portal.

Take down policy

If you believe that this document breaches copyright please contact rucforsk@kb.dk providing details, and we will remove access to the work immediately and investigate your claim. 


\title{
Joint Enterprise and the Role of the Intermediator: Challenges Managing Groupware in Global Virtual Teams
}

\author{
Pernille Bjørn and Jesper Simonsen \\ Computer Science, Roskilde University, Denmark \\ \{pbr,simonsen\}@ruc.dk
}

\begin{abstract}
Managing groupware technologies in global virtual teams is viewed as a process of integrating technology and collaboration. This involves a continual negotiation of the team's goals, processes, and technology. We investigate organizational factors constraining this integration process, by analyzing the failure of integrating groupware into two global virtual teams within industry. We present an empirically driven interpretive case study conducted in a large distributed global organization. Based on the empirical observations, we reveal two organizational factors challenging the integration process: The importance of joint enterprise and the role of the intermediator.
\end{abstract}

\section{Introduction}

In order to achieve synergy and represent the best expertise available in various kinds of projects, there is an increasing need for collaborative work between dispersive participants within global organizations. Information and communication technologies in general, and groupware technology in particular, offers support for such virtual teamwork. In this paper we focus on groupware technology providing a shared repository available any time and any place. Groupware supporting collaborative work in global virtual teams are characterized as open-ended and configurable technologies [21]: They mediate interactions among multiple distributed actors, who not only are users but also manage the system's structure as well as it's content. Organizational models for implementing such technologies in general, and within global virtual teams in particular, have only recently started to take form. Different approaches have been exploring the issue of integrating groupware in virtual teams $[1,2,16,23]$, and it is a well known fact that success with integrating groupware in virtual teams is highly dependent on the introduction process $[6,8,10]$. There exist a need to investigate which issues should be addressed when facilitat- ing the introduction and integration of groupware. We address and analyze the failure of integrating groupware in virtual teams by asking the research question: Which organizational factors challenge the integration process of groupware in virtual teams?

We have conducted an interpretive case study of two global virtual teams within a transportation organization of around 100.000 employees located at sites in Europe, Canada, United States, and Asia. Both teams were formed by top management to develop common processes for doing software development within the organization around the globe. Our analysis elicits two organizational factors constraining the integration process: When participants are unable to negotiate their joint enterprise; and when nobody takes on the role as the intermediator facilitating the integration process. We argue that the introduction of groupware should address these factors, which in turn will support an integration process and aim at establishing a successful virtual collaboration.

The following part of the paper is divided into five sections: Theoretical background presenting resent contributions within the field and introducing core concepts; research method; case study, examining and analyzing the empirical data from the two virtual teams; and finally, a conclusion summarizing our findings.

\section{Theoretical Background}

Recent research has focused on what constitutes success in a groupware integration process. Jarvenpaa et al. [9] examine virtual teams and find that reciprocal trust has an important impact on team success. Kayworthland and Leidner [11] focus on virtual leadership of global virtual teams, identifying several aspects of successful leadership. Maznevski and Chudoba [18] carried out a longitudinal empirical study of three global virtual teams. They find that teams whose interaction incidents are in a temporal rhythm function more efficiently than teams who do not develop such rhythms. None of these researchers have specifically 
addressed the question of technology support. Turning to technology-focused studies, we find research focusing on customizing these open-ended systems [e.g. 7, $24,25]$, though not specifically addressing the issue of integrating groupware within global virtual teams. Only a few studies [e.g. 16, 23] combine interests in both virtual teams, technology, and addressing the issue of integrating groupware and collaborative work. However, researchers studying either organizational aspects of global virtual teams, technology, or the integration process, generally agree that when it comes to starting up a virtual team, technology is required to mediate and support the collaboration. A good technological introduction and integration process are important in fostering success $[6,10]$.

Overall, we view the integration process of groupware within teams as a negotiation/re-negotiation process [1]. A team needs to negotiate their project at its inception and continually re-negotiate their common project throughout the process until the project ends and the final report is completed.

In order to describe more specifically what a team needs to negotiate, we are inspired by literature concerning project management. Lindkvist and Söderlund [15] have addressed the question of "what is going on during project work". They examine the planning and scheduling aspects and identify a significant aspect of project work: The goal. The importance of goals has been investigated by Ferrán-Urdaneta [5], who states that goals have to be clear, measurable, and accomplishable, and general management objectives are not the same as project goals. While there is general agreement that goals are important for project and teamwork, Ferrán-Urdaneta [5] argues for the need for clear and measurable goals, while others state that goals are never clear and measurable but are often unclear and shifting [4, 15]. This does not imply that goals are less important, but rather that they play a different role within the project. For Lindkvist, Söderlund and Engwall [4, 15], goals allow participants to create a division of labor and to continually suggest adjustments and compromises. These important aspects of collaborative project work can be summarized by Wenger's [26] concept of joint enterprise.

A goal is more than a goal, it is a joint enterprise [26]. The joint enterprise comprises the ongoing negotiation of meaning as defined by the participants (the goal) in the very process of pursuing the goal (the team's collaboration process). The joint enterprise is not only intentional but becomes an embedded part of the collaboration by creating relationships of mutual accountability among the participants [26, p. 78]. Joint enterprise contains both the team's goal and the team's negotiated process of how to collaboratively reach that goal.
Olson and Olson [19] describe joint enterprise as the importance of developing a common ground for collaboration. They add that in order to support the collaboration by means of technology this requires collaboration readiness as well as collaborative technology readiness. Groupware systems that include a shared repository are characteristic in the sense that the repository seldom contains a large amount (if any at all) information when the team starts it's project. The information is typically in form of all documents produced by the team and this information evolves as the project evolves. The system's structure in terms of access rights, folder structure, notification functions, support for custom document types (templates), document version control, etc. is a task left for the team to instantiate, configure, and continually maintain [3]. Research within knowledge management systems characterize this as the establishment of three major roles: The producer, the consumer, and the intermediator [17]. The role of the intermediator is defined as managing the system's structure as well as facilitating the users who produce and consume the information recorded in the repository $[17$, p. 61$]$.

In light of these considerations, we can summarize that the integration process of groupware in global virtual teams includes the team's goals, collaboration, and technology. The team needs to continually negotiate what the project is about: Joint enterprise. This includes negotiating how to collaborate and also how to support the collaboration by means of groupware support. Finally, integrating groupware includes the role of the intermediator managing the structure of the system as well as facilitating the shared use of the system.

\section{Research Method}

Our background is based on earlier studies of groupware conducted in a large distributed financial organization. These studies demonstrated that integrating groupware in distributed project settings is significantly more problematic in comparison to other settings, such as organizational units like departments, special interest groups, or teams handling recurrent tasks [3]. The difference in complexity is mainly due to the temporary constellations related to the context of projects. Projects are characterized as a temporary context where different actors meet for a limited time period. We analyzed a range of critical conditions that influence integration of groupware [22], providing us with an initial idea of the conditions related to distributed and collaborative projects. On this basis, we conducted the study presented in this paper.

The empirical data stems from studying two global virtual teams. The teams were observed during the 
course of their projects in 2002 and 2003 and interviews were conducted after the projects had ended in 2003.

In order to get familiar with the company one of the authors was furnished with an office for several weeks. During this time various reflective conversations were held with the team managers and a senior management team. Thirteen sessions were observed where internal consultants reviewed the software work processes as part of both projects. Focusing particularly on the two teams and their collaboration process, we conducted a two-hour focus-group-interview involving both project managers. This was followed up by an individual reflective conversation with each of the project managers lasting two hours each. We also conducted two singleinterviews and one group-interview with participants from the project teams. Analyses of important documents and of the structure and content of one of the teams' Lotus Notes ${ }^{\mathrm{TM}}$ database was also part of the study. At the end of the study, we presented the findings at a senior management meeting, where the project managers reviewed our findings.

\section{Case Study}

The citations below are all taken from interviews with various participants from the two teams in the following referred to team 1 and team 2 .

\subsection{Joint Enterprise: the Story of Team 1}

Team 1 was formed by top management, with the objective to define, develop, and deploy 'one set of processes' for doing software development. The team consisted of 10 participants located in Germany, Denmark, Thailand, Finland, and at two different sites in Sweden. The different participants were chosen to represent expertise from all sites involved. They had a Lotus Notes database set up to support their collaboration, but they never succeeded in integrating this groupware technology into their team work. This is the tale of Team 1, focusing on their ability to integrate groupware into their collaboration.

Team 1 began their project at a workshop where the project manager had planned sessions for all participants to get to know each other and to start developing their joint enterprise. He introduced a knight symbol for the team to identify themselves by inspired by the tale of King Arthur of Camelot [12].

"And then I wanted them to have some kind of symbol, and I had the idea of calling us knights. We are the knights fighting for one common set of processes. I gave them playmobil [knight] figures to put on their desks."
Besides the knight symbol, the project manager also suggested rules for how email communication should be distributed. He arranged weekly phone meetings for all participants, he asked each participant to make a weekly report describing their activities during the week, and he gave them access to their shared Lotus Notes groupware system. In this way the project manager persistently tried to facilitate the team to initiate collaboration. In spite of the manager's good intentions, the participants did not succeed in articulating their work and collaboration at the workshop. A participant describes what he viewed as an unproductive workshop, emphazising difficulties in discussing and deciding on common goals for the collaboration within the virtual team.

"It [the workshop] was managed in a democratic way. [The project manager] had a goal that we should make a vision. But you cannot do that, ten people meeting for the first time, and trying to decide what this team should even be working on. [...] So we should state a vision, but nothing has developed since that. [...] It is easier when a manager enters and states that we have to work in this direction."

It is easier to address direct orders from management than it is to negotiate a shared understanding of a goal, a process, and a collaboration. The manager's "democratic way" increased complexity. However the reason for establishing an international team for this kind of a task is to use experts from all sites to develop the common set of processes that they all should comply with. The necessary engagement, involvement, motivation, and commitment might indeed be dependant on pursuing such a democratic management approach.

The difficulties emerging at the workshop were symptoms of the main issue and challenge within Team 1: A lack of common understanding of their joint enterprise. The participants had not obtained a clear idea of the common goals and objectives. The team's participants mostly continued doing their work as they did before entering the project. For example, one member thought that to maintain a site-local database with no relation to process-definition was the same as contributing to the project. It also became clear that different interpretations of the goal existed not only within the team but also within top management. This in turn effected Team 1 and resulted in members working in quite different directions: Some focusing on safety critical software; some developing common coding standards; and others developing processes for vital software. The participants also had different backgrounds for joining the team. Some were selected because they were the only software process experts 
available at a site and others had a specific interest in code-standards, configuration management, or in software version control. Most participants were busy working in other teams parallel to participating in Team 1. For some this reduced their contribution to only participating in the weekly phone meeting. The result was unsuccessful phone meetings.

"We have a phone conference at least once a week. [...] It seems it don't really work. Even if they are just discussing technical things. There is no discussion."

The project manager explained that difficulties with communication meant that much of his time was spent traveling, trying to get the team to collaborate. He was eager to encourage participants to phone each other to discuss various topics, but none of the members contacted other members. When asked why they didn't contact each other, the participants said they didn't know what they should discuss with each other, so there was no reason for calling. Because the team did not collaborate, they did not succeed in using the groupware technology nor any other kind of technology to support the collaboration: There was no collaboration.

The project manager and the team did not fully succeed in achieving the goals of the kick-off workshop. They did not manage to negotiate the joint enterprise, the process, or the groupware technology. None of the initiatives supporting communication worked as planned by the project manager. When the difficulties concerning communication in Team 1 were later discussed between the project manager of Team 1 and the project manager of Team 2, the Team 2 project manager was also puzzled by the situation. He stated that it seemed that the project manager of Team 1 had done all the right things but was still experiencing problems. The project manager of Team 1 suggested the main problem within the team as follows:

" It's quite important for the group members to ask am I working on the right thing? But we didn't have the time to define it - so we didn't have this one [the alignment tool]"

The knight figure, or the "alignment tool" (a workshop technique including an elaborated question statement about the project), was supposed to create a common ground for the project participants, not only in form of an identity but in the form of concrete guidelines for working.

Different factors appeared to contribute to the failure of the negotiation process at the kick-off workshop. Participants' varying motivations, different cultures, language differences, etc. all appeared to play some part, but a primary factor was that the team was unable to specify what it actually means to develop 'one set of processes'. They were unable to transfer top management objectives into their own goals, tasks, and deliverables. The indefinite nature of 'what' they were supposed to collaborate about constrained the participants in discussing the team's work process and technology use. It was impossible for the team to discuss how to collaborate.

We learned from Team 1, that participants are unable to discuss how they want to collaborate if they do not share an understanding of what they are supposed to collaborate about. The latter is a much more fundamental question, which was not presented to Team 1 in the kick-off workshop. There can be different interpretations of general objectives such as the statement "developing one set of processes", but as a foundation for a single interpretation, the team needs to have a common understanding of what this statement means. As a result, the team did not manage to reach a common ground: They failed to establish a joint enterprise.

Concluding the tale of Team 1, we suggest that an organizational factor that constrains the negotiation of how the team should collaborate (including how groupware should be used to support the virtual teamwork) is when the team is not able to negotiate is the joint enterprise for the project.

\subsection{The Intermediator Role: the Story of Team 2}

Team 2 consisted of five participants located in Canada, United States, United Kingdom, and in two different sites in Sweden. It's objective was to define and pilot "a software configuration management process" to be used throughout the global organization. Team-members were chosen on the basis of their expertise in configuration management. Some also were quite experienced in refining and operationalizing mandates and goals from top management.

The collaboration process in Team 2 was planned around four regular one-week, co-located workshops held respectively in Canada, Sweden, United Kingdom, and Untied States. Despite experiencing various personal difficulties, the team managed to engage in successful collaboration and complete their objective. Team 2 was however unable to integrate groupware in their team work. Even though they all had access to a Lotus Notes groupware system, they ended up mediating their collaboration entirely by phone and email.

The team's initial co-located workshop was held in Canada and focused on negotiating the joint enterprise including the process ahead. The participants negotiated a common interpretation of management's overall objective "to develop and define a common high-level software configuration management process". Team 2 translated this general objective into a project defini- 
tion, which comprises a list of concrete activities for the team to perform.

"The Steering committee said: We want a common high-level process and we want a tool. And we said we are going to take that and make a few objectives. Because we have to put a scope around that. Sure we'll define a process, and we give you a deployment strategy. [...] So we had to bound it a bit. And we came up with objectives and we all agreed to them."

It is evident that being fewer people (five as compared to ten in Team 1) had a positive effect on negotiating the goal, but more crucial is that Team 2 succeed in translating general objectives from top management into workable project goals: The joint enterprise. Having decided on what to collaborate about, Team 2 started negotiating how to collaborate.

“(...) The objective we build together and we build the mandate. And we build team-roles, we used some [...] tools. Here is what we think we will do; here is the project, we find this process, we tried it out, we decided on the tools, and then we looked at potential customers, we did team ground rules."

Even though Team 2 explicitly negotiated how to collaborate at the initial workshop ("we did team ground rules"), they continuously negotiated how to collaborate throughout the whole project period. They negotiated explicitly by reflecting on difficulties in the collaboration activities and by trying to address these difficulties by proposing new rules and norms for their practice. They also negotiated implicitly by participants acting in certain ways, like constraining or enabling other participants ability to act. The negotiation of how to collaborate was thus an ongoing continual process, which primarily took place during the regularly co-located workshops.

While Team 2 managed initially to negotiate the joint enterprise, the question of how their groupware system should support the collaboration was an issue they did not manage to seriously reflect on. Their Lotus Notes system was never really used during the project.

After the initial workshop, the team used email to support the coordination of deliverables and to review comments arising between workshops The team did not attempt though to integrate groupware into this collaboration process. By reflecting on the use of email, it became clear that email resulted in difficulties concerning document location, e.g. where the most recent version of the project mandate was located.

"I will go looking in my emails because I saved them all. And I would have to search them for the project mandate, and I would find them all, and then I would look date wise, and then I would look content wise, and then I would give you one. Is it the right one, is it the current one? I don't know. And if you call [the project manager] you can't trust what he gives you he just lost his complete email database. We have to send him everything."

Participants expressed a need for having all documents available at one shared repository. None of the participants (including the project manager) had an overview of the project documents. This was a situation that created extra work for all participants. When attempting to locate a specific document, members would look into their local email database, sort the emails by date, and then maybe retrieve the right document. When reflecting on this experience, they recognized a need for reducing this complexity in their collaboration. At the initial workshop, one participant considered suggesting using the Lotus Notes system to the team. She was however insecure of her role in the team and did not have the authority needed for pushing this idea further.

"There was some discussion that we should have a common Lotus Notes database. [...] We have one, but nobody put the project schedule in it. [...] That's really embarrassing [not using the Lotus Notes system]. I would have expected it. I raised the question, so I feel that maybe I should have pushed harder to get this working. But I didn't feel the rest of the team was up to it. (...) if you are supposed to be an SCM-expert [Software Configuration Management-expert] why do everything backwards, why do everything the wrong way. That is why I think it is embarrassing. Don't tell anybody about this - it would spoil our reputation."

Even though Team 2 did manage to negotiate their joint enterprise, they did not negotiate how to support their collaboration with groupware: Team 2 "was not up to it". The team had access from the very start of the project to the groupware system, and using it was mentioned at their first workshop. However, as everyone was busy establishing the project and developing a joint enterprise, nobody took any further action concerning the matter of using groupware. Later in the collaboration process, the lack of a shared repository became an issue when the team members experienced problems managing the growing number of (different versions of) project documents. At this point in time the team acknowledged a collective group need for groupware support not like earlier, where just one participant anticipated such a need but was unable to "push harder to get this working".

"We did ask for the database, but there was no kind of instructions of this is the way to use it, this is how you create [...] there is no support from whoever's 
going to support the database that would help you get a good database template."

This situation can be explained by the lack of an intermediator in Team 2. Even though they succeed in negotiating joint enterprise, nobody from Team 2 took the role of the intermediator, and nobody outside the team went in and facilitated the intermediator role. The result was that Team 2 was unsuccessful in integrating groupware to support their distributed collaboration.

In concluding the tale of Team 2, it appears that apart from managing to negotiate the joint enterprise successfully, teams are also required to negotiate groupware support in order to integrate groupware in their collaboration. Managing the process of negotiating how to use groupware and to instantiate, configure, and maintain the system's structure requires a facilitator taking on this intermediator role. We suggest that an organizational factor constraining the negotiation of how groupware should support the collaboration within virtual teams is when nobody takes the role as the intermediator facilitating this integration process. The intermediator role might be established in various ways. Some participants may already be aware of the need for this role from earlier experiences. One participant in Team 2 saw this need, but she did not have the authority to bring this issue on the agenda. The intermediator role might also be taken by a facilitator from outside of the team. Team 2 did in fact (without success) ask for such support.

\section{Conclusion}

We investigated organizational factors constraining the integration process of groupware in global virtual teams, a process of continual negotiation of joint enterprise, collaboration, and the use of groupware. The investigation was an empirically driven interpretive case study, acted out in real-world environments consisting of two global virtual teams within a large, global, and distributed industry.

We agree with earlier research, that it is not sufficient to simply apply groupware by making it accessible to the participants [see e.g. 8, 10, 20]. In both cases presented, groupware was accessible, yet neither team managed to integrate it into their collaboration. It appears, with respect to virtual teams conducting projects, that a successful groupware integration process is highly dependent on conditions formed in the projects' introductory stages.

Drawing on our empirical data, we suggest two propositions about integrating groupware in virtual teams:

(1) Managing the integration of groupware in virtual teams is a process dependent on the negotiation of the joint enterprise for the project. This includes how to collaborate and how to use groupware to support collaboration. The lack of a joint enterprise seriously constrains collaboration as well as constrains introducing collaborative support by means of groupware technology.

(2) Managing the integration of groupware includes a process of structuring the groupware system and it's repository as well as facilitating how to use the system. This process is seriously constrained if no one fulfils the role of the intermediator.

Our first proposition states the importance of negotiating the joint enterprise within project work in virtual teams. We found that Team 1 was unable to negotiate how to collaborate (even though the project manager eagerly tried to facilitate this process), because the participants disagreed in what their joint enterprise was. It is important to notice that embedded in negotiating the joint enterprise is the issue of how to collaborate. In practice, you cannot distinguish between negotiating what the team should aim at (goal) and how to reach this aim (through a process of collaboration).

You might have a negotiation of joint enterprise without addressing how to use technology support, as we experienced with Team 2 . This will also reduce the possibility for successful integration. Our second proposition states the importance of someone filling the intermediator role and thus facilitating the negotiation of how to support collaboration by means of using groupware. Without the intermediator, whether they be a member of the team or a consulting facilitator, the chance for successful integration decreases, even if the team has acknowledged a need for using a shared repository.

We conclude that these two organizational factors challenge the process of managing groupware integration in global virtual teams. First we found that uncertainty on the part of the participants of the joint enterprise for the project constrains the negotiation of how to both collaborate and use groupware to support this collaboration. Lastly we found that without someone taking on the intermediator role, the integration process of groupware into the virtual teamwork is constrained.

We hope our work may inspire future research in the form of descriptive studies of how virtual teams manage the issue of supporting collaboration with groupware, as well as prescriptive studies aiming at developing normative guidelines with regards to obtaining prerequisites for integrating groupware. 


\section{References}

[1] Bjørn, P., "Re-negotiating Protocols: a way to Integrate Groupware in Collaborative Learning settings", in Proceedings of ECIS'03, Naples, Italy, 2003.

[2] Bjørn, P. and Scopula, A., "Groupware Integration in Virtual Learning Teams - a qualitative analysis based on the TAM-model", in Proceedings of IFIP 8.6, Leixlip, Ireland, Kluwer Academic Publisher, pp. 289-312, 2004.

[3] Bødker, K., J.K. Pors, and J. Simonsen, "Implementation of Web-based Information Systems in Distributed Organizations - a Change Management Approach", Scandinavian Journal of Information Systems, Vol. 16, pp. 85-116, 2004.

[4] Engwal, M., "The futile dream of the perfect goal", In Shalin-Andersson, Kerstin and Söderholm, Anders (eds.), Beyond project management - New perspectives on the temporary permanent dilemma, Copenhagen Business School Press pp. 261-277, 2002.

[5] Ferrán-Urdaneta, C., "Teams or Communities? Organizational Structures for Knowledge Management", SIGCPR'99, New Orleans LA, ACM, pp. 128-134, 1999.

[6] Gallivan, M., "Organizational Adoption and Assimilation of Complex Technological Innovations: Development and Application of a New Framework", The DATA BASE for Advances in Information Systems, Vol. 32, No. 3, pp. 51-85, 2001.

[7] Ginsburg, M. and Duliba, K., "Enterprise-Level Groupware Choices: Evaluating Lotus Notes and Intranet-based Solutions", Computer Supported Cooperative Work: The Journal of Collaborative Computing, vol. 6, pp. 201-225, Kluwer Academic Publisher, 1997.

[8] Grudin, J., "Groupware and social dynamics: Eight challenges for developers", Communication of the ACM, Vol. 37, No. 1, pp. 92-105, 1994.

[9] Jarvenpaa, S.L., Kathleen, K, and Leidner, D.E., "Is Anybody Out There? Antecedents of Trust in Global Virtual Teams", Journal of Management Information Systems; Spring 1998; Vol. 14, No. 4; ABI/INFORM Global pg. 29, 1998.

[10] Karsten, H. "Collaboration and Collaborative Information Technologies: A Review of the Evidens", The DATA BASE for advances in Information Systems, Vol. 30, No. 2, pp. 44-65, 1999.

[11] Kayworthland, T.R. and Leidner, D.E., "Leadership Effectiveness in Global Virtual Teams", Journal of Management Information Systems, Winther 2001/2002; Vol. 18, No. 3; ABI/INFORM Global, pp. 7-40, 2002.

[12] Kostner, J., Virtual Leadership - Secrets from the round table for the multi-site manager, Warner Books, 1994.
[15] Lindkvist, L. and Söderlund, J., "What goes on in projects? On goal-directed learning processes", In ShalinAndersson, K. and Söderholm, A. (eds.): Beyond project management - New perspectives on the temporary permanent dilemma, Copenhagen Business School Press pp. 278$291,2002$.

[16] Majchrazak, A., Rice, D.E., Malhotra, A., King, N, "Technology Adaptation: The case of a Computer-Supported Inter-organizational Virtual Team", MIS Quarterly, Vol. 24, No. 4, pp. 569-600, 2000.

[17] Markus, M.L., “Toward a Theory of Knowledge Reuse: Types of Knowledge Reuse Sit $\neg$ ua $\neg$ tions and Factors in Reuse Success", Journal of Management Information Systems, Vol. 18, No. 1, pp. 57-93, 2001.

[18] Maznevski, M.L., Chudoba, K.M., "Bridging Space over Time: Global Virtual Team Dynamics and Effectiveness", Organization Science, Vol. 11, No. 5, September-October, pp. 473-492, 2000.

[19] Olson, G.M. and Olson, J.S., "Distance Matters", Human-Computer Interaction, Vol. 15, pp. 139-178, 2000.

[20] Orlikowski, W.J., Learning from Notes: "Organizational Issues in Groupware Implementation", Information Society Vol. 9, No. 3, pp 237-250, 1993.

[21] Orlikowski, W. and Hofman J.D.,"An improvisational model for change management: The case of Groupware technologies". Sloan Management Review, Vol. 38, No. 2, pp. 11-22, 1999.

[22] Simonsen J. and J.K. Pors, "Conditions for Change Related to Groupware in a Distributed Organization - a Case Study", in Proceedings ECIS'03, Naples, Italy, 2003.

[23] Vreede, G.J., Davison, R.M. and Briggs R.O., "How a silver bullet may lose its shine", Communication of the ACM, August 2003, Vol. 46, No. 8, pp. 96-102, 2003.

[24] Wang, W. and Haake, J.M., "Tailoring Groupware: The Cooperative Hypermedia Approach", Computer Supported Cooperative Work: The Journal of Collaborative Computing, Vol. 9, pp. 123-146, Kluwer Academic Publishers, 2000.

[25] Wasserschaff, M. and Richard, B., "Supporting Cooperation through Customisation": The Tviews Approach, Computer Supported Cooperative Work: The Journal of Collaborative Computing, Vol. 6, pp. 305-325, Kluwer Academic Publishers, 1997.

[26] Wenger, E., Communities of practice - learning, meaning, and identity, Cambridge University Press, 1998. 